\title{
Impact Factor for IMMI; TMS Debuts Materials Needs Exchange
}

\section{themagazine}

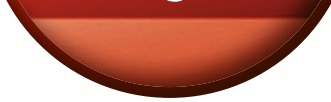

\section{member news}

Share the good news

about your professional accomplishments!

Contact Kaitlin Calva,

JOM Magazine

Managing Editor,

at kcalva@tms.org.

Please note that only

news submitted by

current TMS members

will be considered.

\section{TMS Journal to Receive Impact Factor in 2021}

The TMS journal Integrating Materials and Manufacturing Innovation (IMMI)

has been accepted into the Science

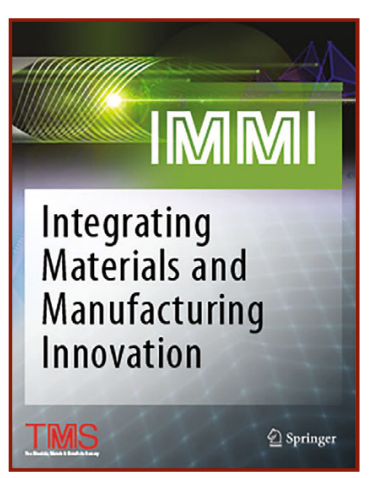

Citation Index

and will

receive its

first Impact

Factor in 2021.

Beginning

with Volume 6,

Issue 1 (2017),

the journal will

be indexed in

the Science

Citation Index

Expanded (also known as SciSearch ${ }^{\circledR}$ ), Journal Citation Reports/Science Edition, and Current Contents ${ }^{\circledR} /$ Engineering Computing and Technology.

"Being accepted into the Science Citation Index Expanded is truly a milestone in the journal's growth as it formally recognizes IMMI's meaningful value to the materials science and engineering community," said Charles Ward, editor-in-chief of IMMI. "To be accepted, a journal must show a consistent level of quality that demonstrates it will provide lasting value to readers."

Launched in 2012, IMMI is a peerreviewed journal that is committed to building a seamless and dynamic materials and manufacturing design framework supporting the accelerated discovery, development, and application of materials and processes. The journal explores innovations from the discovery of materials through their manufacture that support the practice of integrated computational materials engineering (ICME).

"For authors, having IMMI included in the index will mean much greater visibility for their research," said Ward. "Additionally, IMMI's scope provides an outlet for discussion of non-traditional, yet very valuable, research products that have been overlooked by other publication venues."

TMS members can read current and archived issues of IMMI for free by logging in to the TMS Journals web page at www.tms.org/Journals, which also includes a link to the journal's submission site.

\section{TMS Member Nominated for NSB}

Sudarsanam Suresh Babu, professor and University of Tennessee (UT)-Oak Ridge National Laboratory (ORNL) Governor's Chair for Advanced Manufacturing at UT Knoxville, was nominated to a seat on the U.S. National Science Board (NSB) in April 2020. If confirmed, Babu will serve a six-year appointment. The purpose of the NSB is to help shape policy and research for the National Science Foundation, as well as advise members of Congress and the President on scientific matters.

An expert in developing advanced materials, Babu lends his knowledge to many collaborative projects through appointments with IACMI-the Composites Institute; UT's Department of Mechanical, Aerospace, and Biomedical Engineering and Department of Materials Science and Engineering; ORNL's Energy and Environmental Sciences Directorate; the U.S. Department of Energy's Manufacturing Demonstration Facility at ORNL; the Bredesen Center for Interdisciplinary Research and Graduate Education; and the Joint Institute for Advanced Materials.

A TMS member since 1993, Babu has participated in several technical committees within the Materials Processing \& Manufacturing Division. He has also been an instructor for TMS's prominent Additive Manufacturing Materials and Processes Workshop, held for several years in conjunction with the TMS Annual Meeting \& Exhibition and Materials Science \& Technology conferences. 


\section{COVID-19 Materials Needs Exchange}

TMS Connects Members and Resources through Materials Needs Exchange

In April 2020, TMS launched the COVID-19 Materials Needs Exchange as a means of connecting TMS members and/or their employers with organizations on the front lines of the COVID-19 pandemic for the purpose of rendering materials and manufacturing assistance, resources, or expertise. The Exchange is available at www.tms.org/COVID19Materials.

Organizations that can provide materials assistance or expertise addressing the challenges presented by COVID-19 were invited to post a description of what they can offer and contact information on the Exchange. (Please note that only TMS members are permitted to post their expertise as individuals.) Organizations or programs in need of materials and/or manufacturing support were invited to post their requests as well.

"In this time of crisis, many of us are looking for ways we can help our communities, countries, and the worldor we need help ourselves. TMS members are no exception," explained 2020 TMS President Tom Battle regarding the creation of the Exchange. "We, and the companies we work for, constitute a unique resource in this time. The materials we produce, the technologies we use to produce them, and the broad expertise of our membership can be of great value in the world at this time. So TMS is proud to have created a Materials Needs Exchange to connect our wide-ranging capabilities to those in need of it."

The Exchange listings are currently still open to all to review. You can directly contact any of the organizations listed that you believe are a good match for what you or your organization can provide.

Concurrently with the Exchange, TMS also launched the TMS COVID-19 Resource Portal to provide a one-stop gateway to the Society's online content, virtual networking opportunities, COVID-19 related updates, and other resources and support available to our members during these difficult times. See all available resources at www.tms.org/ COVID-19.

Both the TMS COVID-19 Materials Needs Exchange and the TMS COVID-19 Resource Portal are direct results of ideas and input that have been shared and advanced by members through our TMS volunteer structure.

\section{In Memoriam: George T. Murray}

TMS extends its condolences to the friends, family, and colleagues of George T. Murray, who passed away on March 22, 2020, at the age of 93. Murray studied math and physics at the Eastern State Teacher's College in Kentucky and, after a break from his education to enlist in the U.S. Navy, transferred to the University of Kentucky where he earned his B.S. in metallurgical engineering. He went on to earn his M.S. from the University of Tennessee and his Ph.D. from Columbia University. Shortly after, he co-founded the Materials Research Corporation, where he worked as the director of research and, later, as corporate vice president. In 1978, Murray made the switch to academia, serving as a professor of materials engineering at California Polytechnic State University, San Luis Obispo until his retirement in 1993. He co-wrote the textbook, Introduction to Engineering Materials, and has authored more than 30 articles for technical journals and trade magazines. Murray joined TMS as a member in 1960 .

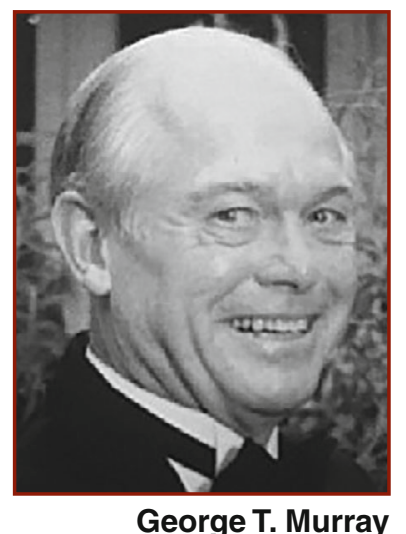

George T. Murray 